\title{
4 Crafting Certainty in Liquid Worlds: Encountering Climate Change in Kiribati
}

\subsection{Introduction}

\begin{abstract}
Societies have always read the weather for signs but generally they were signs of stable climates. Now, however, the weather is being read for its powerful, unpredictable 'wanderings', for climate instability.
\end{abstract}

(Szerszynski \& Urry, 2010: 4)

Szerszynski and Urry suggest, using metaphors of orientation, that environments affected by climate change are lost, unfixed, with no destination ahead. They further point out that atmospheric science exposes the weather to technological intervention in order to reign in it (Szerszynski \& Urry, 2010: 4). One could unpack Szerszynski and Urry's passage and ask: What is the need for reading the weather if it is stable and predictable? And, conversely, how can one read the weather if it is absolutely contingent, uncertain, or chaotic? Reading the weather becomes a skill when the environment rests on principles of uncertainty and certainty, of contingency and stability.

In this article, I explore how people in the Pacific live in and make sense of changing environments. The navigation skills found in Kiribati will provide the empirical material for this purpose. I argue that both certainty and uncertainty are key to understanding how people navigate the oceans and predict changing weather patterns. Certainty and uncertainty exist, not in a dualistic relationship, but in an interconnected and organic relationship side-by-side. One does not exclude the other. And I show that engaging in understanding how the environment works and anticipating how the future will unfold are still important to people living in environments affected by the unpredictable wanderings of global anthropogenic climate change.

Places impacted by global climate change have been described as increasingly uncertain for the people living there as the environment is dramatically reconfigured (Crate, 2011: 179-80). Hence, tremendous scientific efforts are invested in modelling the impact of climate change in the future. But numerous uncertainties and unknown factors are unavoidable (see for example Barnett, 2001: 982; Hulme, 2010: 271; Mitchell \& Hulme, 1999: 59; Szerszynski \& Urry, 2010: 1-2). In fact, Michel Callon et al point

Maria Louise Bønnelykke Robertson, University of Copenhagen 
out when examining controversies in scientific and technological advancement that "scientific and technological development has not brought greater certainty. On the contrary, in a way that might seem paradoxical, it has engendered more uncertainty and the feeling that our ignorance is more important than what we know" (2009: 18-19).

Anthropologist Susan Crate claims, in a review of anthropological engagements with global climate change, that climate change disrupts local environmental skills making folk weather forecasting unreliable. She highlights how adaptation practices are destabilized and cultural orientations and symbolic frameworks are challenged when people face the volatility of global climate change (Crate, 2011: 179-80). Populations across the world are losing "the very totem plants, animals, and landscapes that are central to their spiritual orientation" (Crate; Crate \& Nuttall; Cruikshank; Nadasdy; Nuttall et al; Rhoades et al; Salick \& Byg; in Crate, 2011: 180). From this position Crate implies a loss of orientation when climate change disconnects environments into unknown configurations.

While there is no doubt that climate change has dramatic effect across the world I want to revisit and question the assumption that people become lost in a changing world. Instead I will echo Katharina Schneider when she explains the openendedness of fishing movements among the Saltwater People in Papua New Guinea. Movements on the ocean are often unpredictable and surprising (2012: 40) indicating that islanders with their intense orientation towards the ocean inhabit the world not despite of, but because of, fluctuations.

In this analysis certainty and uncertainty should not be considered as in a contradictory relationship. Empirically and analytically they are difficult to single out and isolate from each other. They morph into one another, and the one is merely the other emerging. However, as Boholm reminds us, when she outlines the scope of an anthropology of uncertainty, "[u]ncertainty has to do with what is unpredictable in life [...]. Uncertainty concerns the future [...]. Uncertainty implies recognition of change and awareness that states of affairs are not static; they can alter drastically for better or worse" (2003: 167). I examine how people engage with uncertainties when living with new emerging weather patterns by exploring two different modes of connectivity. John Dewey's ideas on the relationship between nature and experience-in which experience is not superimposed upon nature, but is situated in a natural environmentwill establish the backbone of this analysis. As Dewey succinctly puts it:

[E]xperience is of as well as in nature. It is not experience which is experienced, but naturestones, plants, animals, diseases, health, temperature, electricity, and so on. Things interacting in certain ways are experience [...]. Experience thus reaches down into nature; it has depth. (Original italics, 1958: 4a [sic]).

According to Dewey experience is situated in the interactions surrounding us. Humans as well as non-humans are places in a network of interactions, and it is from here we 
engage our experience of what might be called nature or the environment. That is, experience is internal to, not separate from, nature. So, humans are simultaneously part of a network, as well as busy making sense of it. Connectivity, then, denotes both an idea that humans partake in shaping and forming the world around us, but also denotes an experiential position of how to make and remake the world through our connections to it.

\subsection{The Reception of Climate Change in Kiribati}

The uncertain future was indeed a concern in Kiribati, a small atoll nation in the central Pacific. Anxiousness about the future prevailed here. One of the main concerns was that the sea levels are rising and encroaching on the shores of the small islands. Scientific assessments suggest that climate change will make the islands uninhabitable within this century (Barnett \& Adger, 2003; Storey \& Hunter, 2010). And data collected and represented in models on the government's homepage shows that temperatures, rainfall, sea levels, and ocean acidification have increased in the last 50 years. ${ }^{22}$

Climate change was discussed in the churches, on the national radio from where most people received their daily news, and the issue of climate change was high on the political agenda. Yet, even if climate change was a major political concern on these islands this knowledge was not distributed evenly among the I-Kiribati people. The church, especially the Catholic Church, often referred to the rainbow promise where God promised Noah that the earth would never again be flooded and through this argument rejecting the existence of climate change. And when the President addressed the village elders, which he did during government elections taking place during my fieldwork in 2011, rumours had it that it was more important to bring bags of kava in order to secure votes rather than discussing the pressing issues of climate change.

Also in 2011, the I-Kiribati government arranged a Climate Change Summit where all the Ministries, NGOs, and village chiefs in Kiribati debated how to integrate the issue of climate change into the national development plan, and President Anote Tong announced that climate change will have to be considered in every political decision in the future. This may seem contradictory when the churches, which are considered important institutions, were not aligned with this mission, and, furthermore, when you still find that people did not know about the issue of climate change. However, on the political level Kiribati depended on aid from donors, and that required working within a specific development framework and operating with a global climate change discourse. Among the villagers, on the other hand, it was not as straight forward.

22 See http: //www.climate.gov.ki/changing-climate/. Accessed 28 June 2013. 
Here, global climate change was entangled in place-based concerns about religious or chiefly authority.

But, nevertheless, people still tried to understand the environment. They tried to make sense of its emerging patterns. And when the question was raised, during the Climate Change Summit in 2011, whether there are any traditional ways of managing environmental change a representative from one of the NGOs answered "If the big waves comes we all go down to the beach with our knives, and show the waves that we are not afraid of them. We can do something like that.” This suggestion might seem bizarre. Waves do not care for knives. You cannot cut a wave in half. But considering that in Kiribati it has been believed that with appropriate rituals, such elements as the sun, the winds, the tides, the sea, and the rain could be influenced and used for the benefit of man:

Natural signs like lightning, cloud formations, and the behaviour of birds were interpreted by the priests and prophets and used by the sorcerers (McDonald 1982: 12).

So even if the data collected the past 50 years shows a clear trend, and even if the scientific projections for these islands seem convincing, there was no single way the scientific data and knowledge were received among the people living in Kiribati. Rather, this was a matter for empirical investigation. In this chapter I examine the skills of one particular person, Teueroa. She is an I-Kiribati navigator who can travel between islands in the Pacific Ocean, and she can read the weather. Her skills rest on generations of knowledge carefully passed down through family lines. The skills have continually been tested and adapted to changing natural and social conditions, enabling interaction with the environment and between islands throughout history.

What caught my attention about Teueroa's skills was that, despite being an authority on environmental knowledge in Kiribati, she entirely refused the scientific idea of global climate change, and, even more surprising, she rejected the idea that the environment was changing in new and unfamiliar ways. To her, the uncertainty of the future was not as much a concern as it was an existential condition. This was surprising to me, and I wanted to understand her rejection: How can a woman who is sensitive to the slightest change in her surroundings, who has intimate knowledge of the waves, the wind, and the currents reject the idea of global climate change? Teueroa's stories and skills illustrate that the increasing technoscientific intervention, monitoring changes in temperature, precipitation patterns, and sea level rise, is not the only way of understanding emerging weather patterns. There are many other ways people are attuned to the ways the world is changing. And I furthermore show that skills and knowledge are not simply undone with the onset of climate change. In fact, these ancient skills play a part in crafting certainty in places undergoing climate change. 


\subsection{The Navigator: Skills for Reading the Weather}

Tabouea: 'The families who have the skills of navigation they keep them to themselves. And the person who has the skills will choose very carefully who of their children they will pass the skills on to'.

Maria Louise: 'What kind of character are they looking for?'

Tabouea: 'They are looking for someone who is quiet and don't talk too much. Someone who is shy'.

It was Tabouea and her husband Mauia, an I-Kiribati couple in their early thirties, who explained to me how people are chosen to receive the skills of navigation. At first, I interpreted this quality of shyness in the navigator to only serve the protection of the secrecy of the skills (Grimble, 1931, 1972). However, as I came to know the navigator, Teueroa, I began to understand that to become a navigator required someone who could enfold the skills, someone who would devote themselves to the skills. When Teueroa began telling me stories about her life I learned that often it was the skills themselves, which to a large extent shaped Teueroa's course, not just on the ocean, but also in her life. Teueroa was an elderly lady, suffering from Arthritis and type 2 diabetes, like so many other aging women who had lived arduous lives on the island, and so her journeys on the oceans had become more and more seldom.

The navigation skills are considered family property, and, as I was explained, navigators would rather die with their skills than give them to someone undeserving. I heard stories of researchers interested in navigation arriving in vain and leaving empty handed because they found no navigator willing to talk to them. When I explained that I was interested in learning about the navigation skills people answered that no one could teach these skills, and that the navigators guard their skills as a secret. However, Teueroa had a desire to give the skills away, something that was unusual, and so she was different from the impression many of my respondents had given, namely that they were a select few, both shy and unwilling to share the secrets of navigation. The reputation of navigators were such that locals knew Teueroa was one of the most skilled navigators on Tarawa, but had no idea what she looked like, or where she lived. Perhaps this was so because Teueroa was truly so reclusive, or perhaps my informants knew more than they let on, and tried to protect the secrecy of the navigation by not sharing any information they might have had about her with me.

It was the family I lived with during my fieldwork who arranged the first meeting between Teueroa and I. They knew Teueroa as a relative from their extended family. Even so, arranging this meeting took more than one month, as it required a formal invitation and Teueroa's lengthy consideration. Since that first meeting, despite her age and deteriorating health, she made her way to the family where I lived every Sunday to teach me the navigation skills. Sitting inside one of the thatched huts (kiakia), and with small pieces of wood representing the stars and the moon arranged on a board, she demonstrated how celestial bodies travelled across the night sky. 
Teueroa opened all our lessons (reirei) by making food offerings to stars and smoking the local tobacco to honour the stars. She explained that in Kiribati the stars are considered ancestors, and these acts of offerings pleased them. When I asked her why she did not teach me by directly observing the night sky and the stars, which she showed so much respect, she simply replied that I was not ready to learn in that manner. This echoes other accounts of how navigators learn their skills inside the huts as opposed to under the open sky. The navigator Biria from the island Butaritari had to learn inside the public meeting house "178 stars, constellations and nebulae; to indicate their relative position [...] and to say at what height above the eaves (i.e. the horizon) anyone of them might be seen at sunrise or sunset at different seasons of the year" (Grimble, 1972: 218). Even if I was not aware of it at the time, Teueroa was not simply explaining her knowledge to me, she was more generally teaching me. In this she was a woman of authority. For hours, Teueroa, the family I lived with, and I sat cross-legged in a circle, and in Teueroa's solemn but patient way she taught me the skills and told me stories. If nearby children made too much noise she glared at them and shushed them. If they continued she never hesitated to slap them across the arm or the thigh. She alone decided what I could learn, and what knowledge was too secret to be shared. And she constantly tested me by seeing how well could I retell the stories she told, or identify various stellar constellations in the sky at night.

As argued earlier Teueroa's skills as a navigator not only served to keep her on course when travelling the oceans; they also shaped the course of her life and the contours of her personality in many ways. In the following I will explore one particular event in Teueroa's childhood. Throughout her life she had to endure several tests to demonstrate her worthiness as a navigator. Some of these tests were more straightforward than others. It could be naming stars and constellations in the communal meetinghouse (te maneaba) in front of village elders. But as a young girl, the first test she had to endure was being thrown in the ocean and abandoned there by her father.

\subsection{If You Are Going to Be a Traveller...}

On these small atolls the ocean and its rhythms, the endless sound of the waves breaking on the reef, and the tides, constantly contracting and expanding around the islands like a heartbeat, feature in most aspects of daily life. Navigational skills have allowed a handful of people from these islands to align themselves in this ocean world and to predict sailing and weather conditions. Navigators have interpreted the formation and colour of clouds to identify islands over the horizon. Birds and certain species of fish would give an indication of the distance to land. Star paths were followed when travelling greater distances. Most impressively, ocean swells, reflected from far away islands and reefs, would echo through the 
canoe and its navigator, and would be recognised like the face of an old friend (Akerblom, 1968: 116). However, several I-Kiribati got lost at sea during my eight months of fieldwork, and from time to time you can read astonishing stories of how I-Kiribati fishermen have survived long periods of drifting lost at sea. ${ }^{23}$ So however much can be understood and learned about travelling the ocean, navigation in the Pacific remains a risky activity made hazardous by unsuspected waves and reefs, strong currents, and outbreaks of bad weather.

Teueroa's father passed on the navigation skills of his ancestors to her, including knowledge of the stars, the weather, and the currents used for sailing. But, more than this, from an early age Teueroa was also taught how to be in the environment. She had to know the ocean, how it felt, tasted, and behaved, when it would be welcoming, dangerous, or deceitful:

The first time I learned to travel I was 14. I was on the local canoe with my father from the island Maiana. My father asked me to pick up something at the bottom of the canoe, as I leaned down my father pushed me into the sea. So I fell into the sea and you know how I tried to survive. I was crying and calling my mother, but my father sailed away. I can't really remember how long I was in the sea for, but when I looked at the canoe, it sailed away and disappeared. I was crying in the middle of the ocean, calling my mother. The ocean there is very dark and deep. But that was a test for me to overcome the fear of the sea, because if you are going to be a navigator, if you are going to be a traveller, you cannot be scared of the sea. My father came back. He put me on the front of the canoe and then the he said: 'tell me, where is the land?' I pointed, and when it was wrong I got smacked. Then I tried to remember again what I had learnt. So I identified the land according to the cloud.

When Teueroa's father threw her in the water, time was momentarily suspended as she found herself floating; this unknown space created nonlinear time. She could not say how long she spent in the ocean even though her memory of the event was vivid, and every detail was conveyed. In that moment her senses were sharpened, and her mind absorbed all impressions.

Human geographer Nigel Clark argues for the idea of excess, which can unpack Teueroa's experience in the ocean. He draws on Deleuze's criticism of transcendence, arguing that all forces or energies are immanent or enfolded in the material world, and Lovelock's Gaia hypothesis, a theory maintaining that it is the collective role of the world's biosphere which maintains the atmosphere in states far from equilibrium, never totally ordered, never totally chaotic. Clark suggests that we can never totally account for any forces or events. In other words, they are irreversible, and he views the human as embodying something:

23 See for example 'Kiribati Fishermen Rescued After Four Weeks Lost at Sea,' ABC News 8 May 2013, http: //www.abc.net.au/news/2013-05-08/an-fishermen-rescued-after-four-weeks-lost-at-sea/4676278 
of the other-than-human: traces of storms that have been weathered, stirrings of the earth that have been ridden out, poisons and infections that have been stomached. And the echo of events in the solar system and the wider cosmos. Some of these forces and processes, as we now know, come back to us bearing our own imprint (2005: 179).

With this approach in mind, that the connections making up the world are always more than we can imagine, they are irreversible, unpredictable, and echoing earlier connections I want to raise the question: why does Teuroa's father throw his daughter in the ocean? What kind of cruel exercise is this? We can only speculate, as Teuerao's story does not reveal an answer.

Teueroa learned much of her knowledge through repetition, memorisation, and models. But being thrown in the ocean was a very different lesson indeed. Her father maintained certainty through repetition of patterned connections in his teachings, but also instilled uncertainty by abandoning his daughter in the ocean. I argue that he was teaching her about how the world works, and his lesson was that the world can be treacherous, unreliable, and uncertain. Teueroa's experience in the water underscored the "volatility and unpredictability of many of the physical processes that human beings and other living things rely upon" (Clark, 2010: 32-3), as waves washed over her, and the current dragged her body along. There was no one, or no single thing controlling this event. There is no centralized hierarchical direction, as John Urry would put it (2003: 10; 2005: 8). While floating there at the mercy of the forces surrounding her, she was no doubt connected to and learning about the environment. Not by quantifying it or observing its parts, but by qualifying it, being in it, feeling it on her frail, young body.

I suggest this exercise was a demand on her father's part to remain humble in her connection to the environment. He demonstrated that navigators too loose their way, their orientation, and their ability to align themselves in the ocean world when they find themselves in connections that cannot in any easy way be reversed. He reminded her that she was not over and above the environment simply because she could make abstractions of it. She was not a spectator describing nature from the outside (Prigogine \& Stengers, 1986: 300). More precisely, she was part of and in fact immersed in an animated, unpredictable physical world (Hastrup, 2012: 21). She learned that you cannot trust without the possibility of betrayal, and you cannot be certain without the possibility of uncertainty.

However traumatic this experience was for Teueroa as a child, she actively used what she had been taught in her role as a navigator throughout her life. In 2009 Teueroa was called upon for assistance when a ferry capsized on its way to Maiana, one of the outer islands. The Royal New Zealand Air Force sent an aircraft, and the government patrol boat was sent out to rescue the 55 passengers. Teueroa was also asked to be the captain of a boat that collected survivors and bodies. 
Many of them could not be taken back. They had been half eaten, or large parts of their bodies were missing. The government patrol boat went west, but I guided my boat east, and there I found a lot of bodies as soon as I found the current. Once we were in the current, I said to the crew 'let us turn off the motor, let us float'. In this way we could hear if anybody screamed for help.

Teueroa did not know the course of the boat, nor even what her destination was. Nevertheless, she found what she was searching for. Even with her authority as a Captain, Teueroa did not attempt to direct the boat. In other words, she is not attempting to master the situation-she is wandering, as Szersynsky and Urry put it in the introduction. Floating is once again the theme. She accepts that the forces surrounding her cannot be known, and she used this mode of connectivity to find the bodies of the capsized ferry.

The idea of connectivity is not foreign to anthropological literature on Oceania. In what has become a modern classic "Our Sea of Islands" (1993), the Tongan and Fijian anthropologist Epeli Hau'ofa attempts to reconceptualise the dominating Western view of Pacific islands as "much too small, too poorly endowed with resources, and too isolated from the centres of economic growth for their inhabitants ever to be able to rise above their present conditions of dependence on the largesse of wealthy nations" (Epeli Hau'ofa, 1993: 4). According to Hau'ofa, this view overlooks the myths, legends, and oral traditions that by no means conceive of the world as fragmented, tiny, and poor in resources:

The world of our ancestors was a large sea full of places to explore, to make their homes in, to breed generations of seafarers like themselves. People raised in this environment were at home with the sea. They played in it as soon as they could walk steadily, they worked in it, they fought on it. They developed great skills for navigating their waters, and the spirit to traverse even the few large gaps that separated their island groups (Hau'ofa 1993: 8).

In a conceptual move away from a view of fragmented Pacific islands, Hau'ofa advocates a view of a sea of islands connected through kin, exchange, and voyaging routes. Also concerned with connectivity, Carlos Mondragón explores how the Torres people of Vanuatu understand and represent the connections and transformations of themselves and their islands through ancient exchange cycles with other islands and, since then, through the contact with non-Oceanic people (missionaries, colonial administrators, and plantation recruiters) (2009: 117). He describes the maritime and insular milieu of Melanesian life in the Torres as a complex interweaving of land-and sea-scapes, personhood, and topogeny (2009: 116). In Mondragón’s words:

(Is)lands and their maritime milieu are visualized as interconnected media through which a tracery of aquatic roads and bush paths are constantly being renewed or made redundant by the ongoing circulation, the ebb and flow, of persons and things (2009: 123). 
But through Teuerao's other accounts and stories I learned that being embedded in irreversible environmental connections was not the only way she was attuned to the world. Teueroa explained that Bakoa, the shark and the spirit of the ocean, and Tabwakea, the sea turtle and the spirit of the land, had since the beginning of time been in a competitive and struggling relationship. However, there exists important ways to reconcile their struggle with each other or to correct imbalances:

Teueroa: "Sometimes when you want to go to the sea, you bring Tabwakea, and when you come out from the sea you bring Bakoa".

Maria Louise: "What do you mean?"

Teueroa: "I mean all the natures of Bakoa, you bring it to Tabwakea, just to try and make them friendly with each other."

Maria Louise: "What can you bring from the ocean for example?"

Teueroa: "Some of the grass from the deep ocean, like trees [seaweed] from the deep ocean. You bring it onto land. And you bring the flowers from the land and give them to the ocean."

There were other taboos that Teueroa had to adhere to as a navigator. The sea turtle, Tabwakea, the spirit of the land, but also, paradoxically, the spirit of the navigator (see also Teiwaki, 1988: 36), was forbidden for Teueroa to eat. One afternoon when a sea turtle was caught by a villager nearby, and everyone was engaged in eating its bright red meat I realized that this taboo not only applied to Teueroa. As she was teaching the skills of navigation, it also applied to me. She explained to me that if I was ever lost at sea Tabwakea could guide me home, and therefore it was important that I always declined to eat the sea turtle.

In addition, during one of our first meetings Teueroa told me was that when she was born her father took her umbilical cord and sailed into the ocean where the current ends, that is, where the ocean is very deep. He put the umbilical cord into his mouth, jumped onto the outrigger, and then proceeded to jump into the water. After swimming for a while he spat out the umbilical cord, and allowed it to sink into the deep ocean. He swam in a backwards motion to the canoe and sailed home. The story is rife with puzzling elements. Teueroa was never able to provide an answer as to why her father had left her umbilical cord in the ocean. She did however offer an explanation as to why he had swum to the canoe backwards: "It was so that he could keep an eye out for the creatures of the ocean." Her father's ritual is a variation of a well-known ritual in Kiribati described in "Kiribati: Aspects of History":

When the [umbilical] cord fell off, one of the baby's grandfathers wore the cord on his right wrist for three days. It was then carefully wrapped and put away in a safe place. It was believed that if a rat ate it, for example, then the boy would be mischievous in later life. In the case of a baby girl, the cord was worn by one of her grandmothers. This was done so that the child would follow in the footsteps of its elders (Tito et al, 1979: 15). 
Teueroa's father did not tie the umbilical cord to an older female relative as a way of connecting and grounding her within the extended family. Rather, he allowed it to descend into the deep ocean connecting and grounding her in this fluid space. He managed to effortlessly combine two apparent opposites: after establishing an intimate kin-like relationship between Teueroa and the ocean, he still made sure to keep an eye out for the creatures of the ocean-thus combining loyalty and betrayal, the secure and the treacherous. The landscape is then not a neutral background to human activities, but is a relationship of exchange as equally family and enemy.

In the accounts the connectedness between ocean and land, spirits and humans appear, not as irreversible, surprising, and with no element of control, rather the navigator can correct imbalances and influence the way connections interact. Philippe Descola's examination of the Tukano tribe of the Amazonian north-west can illuminate this variation in connectedness. Descola uses a thermodynamic model to describe a cosmos as an immense yet closed circuit encompassing the entire biosphere. In order to avoid entropic states in this cosmos exchanges of energy have to be carefully organised:

For example, when a Desana [one of the sixteen tribes that make up the Tukano group] hunts and kills an animal, a portion of the potential of the local fauna is cut off and is transferred into the human domain when that game becomes food. It is therefore necessary to ensure that the needs for human subsistence do not endanger the good circulation of the flows of energy between the different sectors of the world. And it is the responsibility of the Desana to keep watch on the situation and compensate for the losses that are caused by what they take from non-humans (Descola, 2012: 482).

So it is a balanced flow of energy that ensures the survival of the world, and if the balance is off, if too many animals have been hunted, this imbalance can be corrected through sexual abstinence or through the exchange of souls, that is, sacrificing a member of the tribe, in return for game (Descola, 2012: 482-3).

Descola describes a finite circuit humans can tinker with and adjust in order to ensure that it works well, contrary to Clark's idea of (infinite) excess outlined above. However, the idea of correcting connections into balance cannot account for Teueroa's experience of being abandoned in the sea. The oceanic connections she suddenly found herself embedded in were entropic and irreversible and could not be controlled or appeased, neither cognitively nor spiritually, in any meaningful way. Rather, it was a mind-independent uncertain reality, and there is no way of organizing it to rein it in. However, when Teueroa performed rituals to reconcile Bakoa and Tabwakea, refrained from eating the meat of the turtle, or when her umbilical cord was given to the ocean, it was exactly the kind of tinkering Descola describes, which ensures that the world worked well. So Teueroa was attuned to the world in more than one way. I want to momentarily dwell on what takes place after Teueroa's father returned to her in the ocean as it illuminated the transition from one mode of connectedness to another. As he rescued her from the water, he demanded her to set the course and take 
them home. A difficult task when the world seems entropic. When Teueroa was wrong he slapped her face, as if to say: "Wake up! Assume another position in the world." He insisted that she engaged all of what he taught her about how the world worked.

In the following I will explore Teueroa's forecasting skills, as yet another way of connecting (with) the world. However, while the connections were uncertain, irreversible, and mind-independent while Teueroa floated in the ocean, and that she could balance connections through ritual practices, the skills used for prediction are certain, reversible, and mind-dependent.

\subsection{Crafting Futures: The Certainty of Navigation}

How then does navigation actually work? If the lesson of Teueroa's father's was that world is uncertain, and you never know when it will betray you, how can you predict the weather? How are the connections made between stellar constellations in the sky, the journey of the moon, and the weather and ocean around the islands of Kiribati?

Oceanic navigation is a skill found across the Pacific Islands, as it is crucial for connecting people in a region scattered across the largest ocean in the world. While there are many commonalities among the various traditions each is also particular to an island, sometimes even to a single family or individual. Keeping in mind that these are non-written knowledge systems I will briefly outline some of the basic principles by which navigators conceptualize lengthy inter-island canoe trips. Common across the Pacific has been the reliance on knowledge of the stars, sailing directions, and how to read the waves and predict weather (Goodenough \& Thomas, 1987: 3). Navigators constructed charts. Different versions are found across the Pacific, including stick charts made of palm ribs bound together with string of coconut fibre and used to model swell phenomena and their interaction with islands, or star compasses made of sticks and stones showing rising and setting navigation stars (Akerblom, 1968: 105, 117). Living seamarks-a "tan shark making lazy movements, a ray with a red spot behind the eyes, a lone noisy bird” (Goodenough \& Thomas, 1987: 8) could reveal navigators' positions in the vicinity of islands or midway between them. Living seamarks did not serve as markers in navigation, but they were encountered when lost at sea, so that the navigator who had lost his bearings could align himself once more in the island world (Goodenough \& Thomas, 1987: 8).

In the Caroline Islands navigators use the star compass consisting of the four cardinal points and between 28 and 36 additional points indicating the position of rising and setting navigation stars. The stars are so selected that during a sailing season "several stars can constantly be observed at different heights above the horizon" (Akerblom, 1968: 103-105) allowing sailing throughout the sailing season and throughout the night. In the Marshall Islands navigational knowledge is also astronomical, but special attention is paid to the changes in the direction and configuration of swell and waves. The change and configuration of swell indicates 
direction to land and determine the navigator's position in relation to surrounding islands (Akerblom, 1968: 116). In Kiribati very few accounts of navigation exist. There are two reasons for this. Firstly, Kiribati has received less ethnographic attention than many other Pacific islands (but see Gilkes, 2009; Grimble, 1931; Osmond, 2007). It has even been questioned whether the few accounts that do exist, especially those of former Governor Arthur Grimble, who only studied navigation on the island of Butaritari, can be said to be representative of all of the Islands in Kiribati (Akerblom, 1968: 134). Secondly, navigational knowledge is a skill that is considered secret and therefore not easily shared with non-family members (Grimble, 1931: 198).

The few accounts that do exist suggest that instruction in navigation was carried out in a communal meeting house (te maneaba), where the great roof substituted for the sky, and where stars could be imagined in its thatch. Later when sailing on the ocean, the navigator would refer to the sky as "the roof of voyaging" (Grimble, 1931: 197-8). Imagining the sky as a roof, the eastern and the western roof plates make up the entire night sky, and rafters and beams supported this imaginary roof. "Lying across these rafters, like the steps of a ladder up the sky, the astronomer imagines a series of three equally-spaced cross-beams [...] on each slope of the roof" (Grimble, 1931: 198). The beams allowed the navigator to express the altitude of the star, and the rafter allows him to measure its declination (Grimble, 1931: 199).

Teueroa used a method called te raranga to predict the weather. Te raranga literally means the weaver, as when you weave a sitting mat from pandanus leaves. It consisted of 28 small pieces of wood, representing a lunar month, in the shape of a square, with each side of the square consisting of seven pieces. The square was balanced on one of its tips, pointing north, south, east, and west. Teueroa manipulated three additional pieces in the square: the moon (Namakaina), Scorpio (Rimwimata), and the Pleiades (Nei Auti). The configuration in which these three elements appeared indicated how the weather would unfold. The moon travelled clockwise and faster than the stars, which travelled counter clockwise, reconfiguring the moon, Scorpio, and the Pleiades every day. When the moon appeared in the east of te raranga it indicated full moon, in the north it indicated first quarter, in the east it indicated new moon, and in the south it indicated third quarter.

The small pieces of wood indicated the constellations' location in the sky. Therefore, in order to use te raranga for navigation it was imperative to imagine oneself inside it, looking up at the sky and towards the horizon, not outside it observing as a privileged learner. Teueroa's story of being thrown in the water as a child was crucial here. Simply learning about the navigation skills through te raranga would leave the student with the impression that navigation was only a matter of fixing connections and imposing order. Instead navigation was both about imposing order, through te raranga, and about floating within a network of elements with their own forces. This was the interstitial space between certainty and uncertainty where the navigation skills emerged. Teueroa made sense of a changing world through these two methods simultaneously. 
A prolonged drought affected the island during my fieldwork, something many referred to as global climate change. Others referred to the La Niña phenomenon cooling down ocean surfaces thereby limiting evaporation and precipitation. I wanted to talk to Teueroa about the missing rain, and whether she thought it was connected to climate change. It was then I realised that Teueroa did not know anything about climate change. "What is climate change?" she asked through my interpreter. I explained that human pollution of the air and the atmosphere changes weather patterns and makes the climate change, that temperatures and the oceans rise, changing patterns of rainfall and changing the coastline for example through erosion. Teueroa looked at me confused and shook her head. She could not believe such a thing. In one way, I was not surprised to find that Teueroa was not familiar with the scientific knowledge about global climate change. This was true for a number of the informants I spoke to. However, I was surprised that Teueroa had not at least noticed any environmental change, the absent rain, the rising temperatures, or the changing coastline. So, I asked her about the missing rain:

Teueroa: 'I already predicted last year that there will be no rain for seven months. This is the time for rain, but it depends on the moon and the stars, then the dry will continue. There will be a change if the moon and Rwimimwata meet close together on the third day of full moon this will indicate another six months of drought.' Maria Louise: 'Do you think the drought has anything to do with climate change?' Teueroa: 'No, this has nothing to do with climate change; this was already in the stars!'

Firstly, if we try to see climate change as an imbalance in connections as Descola outlined among the Tukano, where humans have endangered the good circulation of the flows of energy between the different sectors of the world (2012: 482) then accepting this flawed circulation would threaten Teueroa's skills and her whole world. Secondly, for Teueroa drought was not an anomaly. Change, irregularity, and uncertainty were already accounted for in Teueroa's skills. There was a particular certainty, time, and space for drought. Teueroa crafted connections between stars, islands, and oceans to make a world where fluctuation was not a symptom of chaos and unpredictability, but an environment that unfolds, in all its variability, according to a careful order.

\subsection{Concluding Remarks}

I have explored how Pacific Islanders make sense of changing environments through the skills and experiences of a navigator. Through Teueroa's accounts she positions herself comfortably between two different philosophical positions. The notion that the world is made of relationships, engaging in known and unknown ways, 
fixing and unfixing, always struggling and co-operating, and the world emerges in these connections. And the notion of organised exchanges of energy, which allows individuals to engage with systems and correct imbalances that could otherwise be said to be out of their control (see also Hayles, 2010: 325).

These two positions allow Teueroa to alternate between different modes of connectivity in which she attunes herself to the world around her. These two modes of connectivity are organised around certainty and uncertainty: as a decentred human, mercilessly at the forces of the world surrounding them; as a subject able to correct and maintain a certain balance in the environment through ritual practices; and as a subject at the centre, which is the one connecting and mobilising a specific network of actors.

Certain connectivity and uncertain connectivity are in themselves two different ways of being in the world. They do not add up. They teach two different things. Yet, they simultaneously do not contradict each other. People inhabit the world through both certainty and uncertainty, and both are a commitment to understanding the environment. Enormously skilled craftsmen, the navigators, perform their work in a hazardous space, the ocean, and their ability to align themselves in the larger universe is impressive. It is as much about crafting certainty and accepting the uncertainties as it is about competence, about devoting a lifetime to understanding the forces around you from the celestial bodies in the skies to the deep blue ocean.

I would like to return briefly to the name of te raranga, the weaver, because it's very name underscores the point I make. The idea of a weaver suggests neat patterns and order. Weaving also requires someone to do the weaving. It requires mastering and making your way towards a known end by crafting specific connections. Throwing a young girl in the Pacific Ocean was also a critical lesson in becoming a navigator. Floating in the ocean does not denote ideas about mastering or order, but rather it denotes ideas about entanglement, of being at the mercy of the surrounding forces, of accepting a place as just another being in the physical world, and of "orderly disorder."

While climate change no doubt severely affects the Pacific Islands, their coastal areas, their natural resources, and their public infrastructure, it is difficult to say anything in general about how notions and knowledge of climate change are received in these societies. Marching to the coast with knives to face the threatening ocean or using the skills of navigation in order to craft certainty are two ways in which the I-Kiribati make sense of the changing climate. I have shown that people are not simply lost in a changing world of global climate change, but that they continue to engage with the world, tinkering with and attuning to change. I have also shown that even if people are authorities of environmental knowledge they may not know about the scientific notion of climate change, and they may even disagree that the environment is changing in new and unfamiliar ways. This raises important questions for anyone involved climate change adaptation or mitigation. How can we best assist people in the challenges they are facing related to climate change without debunking the knowledge and skills, which have allowed them to live on these islands for generations? 